\section{Investigating Novice and Expert Conceptions of Genetically Modified Organisms}

\author{
Lisa M. Potter, ${ }^{\dagger}$ Sarah A. Bissonnette, ${ }^{+}$Jonathan D. Knight, ${ }^{\dagger}$ and \\ Kimberly D. Tanner** \\ ${ }^{\dagger}$ Department of Biology, San Francisco State University, San Francisco, CA 94132; 践artment of \\ Biological Sciences, California State University, Stanislaus, Turlock, CA 95382
}

\begin{abstract}
The aspiration of biology education is to give students tools to apply knowledge learned in the classroom to everyday life. Genetic modification is a real-world biological concept that relies on an in-depth understanding of the molecular behavior of DNA and proteins. This study investigated undergraduate biology students' conceptions of genetically modified organisms (GMOs) when probed with real-world, molecular and cellular, and essentialist cues, and how those conceptions compared across biology expertise. We developed a novel written assessment tool and administered it to 120 non-biology majors, 154 entering biology majors, 120 advanced biology majors (ABM), and nine biology faculty. Results indicated that undergraduate biology majors rarely included molecular and cellular rationales in their initial explanations of GMOs. Despite ABM demonstrating that they have much of the biology knowledge necessary to understand genetic modification, they did not appear to apply this knowledge to explaining GMOs. Further, this study showed that all undergraduate student populations exhibited evidence of essentialist thinking while explaining GMOs, regardless of their level of biology training. Finally, our results suggest an association between scientifically accurate ideas and the application of molecular and cellular rationales, as well as an association between misconceptions and essentialist rationales.
\end{abstract}

\section{INTRODUCTION}

Every day biology undergraduates file from lectures halls, libraries, and laboratories with their minds abuzz with biological concepts. Yet the degree to which students apply those concepts to everyday life is an open question. Indeed, from healthcare to climate change to biotechnology, the challenges facing modern society demand an expertise in underlying biological principles in order to find solutions. Partly for this reason, the collaboratively published document Vision and Change in Undergraduate Biology Education has urged biology educators to encourage expert thinking in their students (American Association for the Advancement of Science, 2011).

Experts connect ideas from diverse subjects to build their worldviews (Bedard and Chi, 1992). Previous studies have shown that using relevant biological problems as learning tools can help bridge the gap between science learned in the classroom and the real world (Zeidler et al., 2005; Wu, 2013; Sinatra et al., 2014). While many examples of such biological problems exist, genetic modification in particular is a complex concept that relies on in-depth understanding of the molecular behavior of DNA and proteins (Newman et al., 2012). At the core of this understanding is what is often termed "the central dogma," which describes how information is stored in DNA, copied into a newly built RNA molecule, and used to make proteins that carry out cellular functions. Many educators may assume that students with a biology degree are more equipped to understand the complex science behind genetically modified organisms (GMOs) than the general public; however, the central dogma has been a well-documented challenge for undergraduates (Sinatra et al., 2014; Newman et al., 2016).
Diane K. O'Dowd, Monitoring Editor Submitted January 6, 2017; Revised May 10, 2017; Accepted May 16, 2017

CBE Life Sci Educ September 1, 2016 16:ar52 DOI:10.1187/cbe.16-11-0333

*Address correspondence to: Kimberly D. Tanner (kdtanner@asfsu.edu).

(c) 2017 L. M. Potter et al. CBE-Life Sciences Education @ 2016 The American Society for Cell Biology. This article is distributed by The American Society for Cell Biology under license from the author(s). It is available to the public under an Attribution-Noncommercial-Share Alike 3.0 Unported Creative Commons License (http:// creativecommons.org/licenses/by-nc-sa/3.0). "ASCB ${ }^{\oplus "}$ and "The American Society for Cell Biology ${ }^{\circledR "}$ are registered trademarks of The American Society for Cell Biology. 
One barrier to conceptualizing GMOs is the social implications that can make the topic contentious (Sadler, 2004, Sadler and Zeidler, 2004). Some members of society are suspicious of GMOs, calling genetically modified crops "Frankenfoods" and even destroying test fields (Alberts et al., 2013; Fields of Gold, 2013), despite evidence that GMOs pose little threat (National Academies of Sciences, Engineering, and Medicine, 2016). One explanation for this reaction is what cognitive psychologists call essentialism (Wagner et al., 2010). Essentialism is a way that humans intuitively organize information encountered in the world by creating categories, each defined by an underlying essential property that cannot be divided, shared, or changed. The observer assigns an essence to a new concept based on its outward characteristics (Gelman, 2003). For example, if you see a black-and-white spotted dog on the street, you would call it a Dalmatian. Even if the owner had dyed the dog's fur pink, it wouldn't change the Dalmatian essence of the dog. This type of categorization works well in everyday life but may be more complex in the molecular world. For example, if you learn in biology class that DNA is the "blueprint of life," then you may intuitively view an organism's DNA as its essence. Therefore, you would view modifying DNA as changing the essential nature of the organism, which might result in your negative reaction toward GMOs (Wagner et al., 2010). Imagine the Dalmatian owner had altered the dog's genes to breed a line of Dalmatians with pink fur. An essentialist thinker would view these dogs to be fundamentally different from an average Dalmatian; by altering the DNA, the breeder changed the essence of the Dalmatian. In contrast, a biology expert might override this intuition with his or her deep knowledge of cells and hold that altering a small piece of DNA does not change the nature of an organism; the dogs are just pink Dalmatians. Previous research has shown that, in the classroom, essentialist thinking may underlie students' understanding of the relationship between DNA, seen as an organism's "essence," and traits, its "observable properties" (Coley and Tanner 2012, 2015). If essentialism persists among university students, it may inhibit their ability to apply knowledge of the molecular behavior and structure of DNA to explain a real-world biology problem, including in the context of GMOs.

Many studies have gauged public attitudes toward and perceptions of biotechnology and GMOs (Stewart et al., 2000; Dawson and Schibeci, 2003; Dawson, 2007; UK Department of Business Enterprise and Regulatory Reform and Sciencewise, 2009; Legge and Durant, 2010; Wunderlich and Gatto, 2015); however, the majority of these were conducted outside the United States, and none targeted university biology majors' conceptual understanding of GMOs. Additionally, while a number of tools have been developed to assess university biology students' understanding of genetics at the molecular and cellular levels (Bowling et al., 2008; Smith et al., 2008; Smith and Knight, 2012; Newman et al., 2016), none of these evaluate whether students can apply that basic knowledge to novel contexts such as genetic modification. Studies that have investigated the application of knowledge of molecular mechanisms to complex, organismal processes (Duncan and Reiser, 2007; Agorram et al., 2010; Marbach-Ad, 2010; Tibel and Rundgren, 2010; Newman et al., 2012) have indicated that biology undergraduates do not readily transfer knowledge from one context to another. Nevertheless, whether undergraduate biology education equips students to evaluate societal concerns related to the genetic modification of crops or animals remains largely unexplored.

With this in mind, we investigated conceptions of GMOs held by college students by addressing the following questions: 1) How do individuals with varying levels of biology expertise explain GMOs as they would in everyday life? 2) How do they explain GMOs in a biological context? 3) How do they explain GMOs when cued for essentialism? 4) To what extent do undergraduates have the conceptual understanding of the molecular and cellular processes underlying GMOs? 5) How do their explanations of GMOs compare with those of putative biology experts, biology faculty?

\section{METHODS}

To investigate conceptions of GMOs among college-level students, we developed a novel written assessment tool (Box 1) and administered the assessment to populations with varying amounts of formal biology education. In the following sections, we describe the development of the assessment tool, the recruitment of participant populations, and the analytical approaches used to compare explanations within and across participant populations and assessment items.

\section{Assessment Tool Development}

Our novel written assessment tool introduced the nine assessment items in a specific order that prompted explanations of

\section{Box 1. Assessment tool (see Supplemental Figure 1)}

Phase 1: Real-world assessment prompts

Participants shown a graphic of a real-world advertisement containing the phrase: "non-GMO corn."

1. I have heard of a GMO. $(\mathrm{Y} / \mathrm{N})$ Where have you heard of a GMO?

2. How would you explain to a professional colleague what a GMO is?

Phase 2: Molecular and cellular assessment prompts

Participants read the following paragraph:

Several varieties of corn in the USA are considered to be genetically modified organisms (GMOs) that are resistant to insect pests. Scientists transferred a gene into the corn's DNA, resulting in a trait that is toxic to the insect pest.

3. How would you explain to a professional colleague what the relationship is between traits and DNA?

4. The genetically modified corn's DNA is toxic to the insect pest that eats the corn. (Likert scale)

Phase 3: Essentialist assessment prompts

Participants read the following paragraph:

The gene that was inserted in the corn's DNA was taken from a species of bacteria. This gene produces a toxic protein that kills the insect pest. The toxic protein is only made by the cells of the genetically modified corn's stalk and not made by the cells of the genetically modified corn kernels.

5. I consider this genetically modified corn with a bacterial gene to be:

A variety of corn

A variety of bacteria

A hybrid of corn and bacteria

Neither corn nor bacteria

6. The bacterial DNA is present in the cells of all the parts of the genetically modified corn. (Likert scale) 
GMOs across four different contexts: phase 1: real-world assessment prompts; phase 2: cellular and molecular assessment prompts; phase 3: essentialist assessment prompts; and phase 4: attitude assessment prompts. The tool consisted of open-ended and closed-ended probes. As explained below, the current work analyzed six of the nine assessment items. The analyzed items are included in Box 1. After completing the assessment, participants responded to a demographics survey. We describe the development of the prompts and the demographics survey in detail in the following sections.

Phase 1: Real-World Assessment Prompts. Participants first saw a graphic of a real advertisement that contained the phrase "non-GMO corn" to orient students toward thinking about GMOs as they would in everyday life. They then responded to three assessment items that elicited their explanations of GMOs in this real-world context. These prompts, which we refer to as real-world prompts 1, 2, and 3 (Box 1), evaluated the information the participant used to explain GMOs. We excluded one prompt from analysis, "A person's body responds differently to GMO corn than to regular corn," due to the lack of agreement among the putative expert biology faculty population.

Phase 2: Molecular and Cellular Assessment Prompts. To uncover participants' understanding of the role of molecular and cellular mechanisms in GMOs, we introduced an information paragraph about genetically modified corn to cue participants toward thinking about GMOs in a biological context. After reading the passage, participants responded to assessment items 3 and 4 (Box 1). The goal of these assessments was to reveal the extent to which each participant understood gene expression on a molecular and cellular level. The first item asked participants to explain the relationship between traits and DNA. Next, participants responded to a challenge statement that cued them to apply their understanding of traits and DNA to the genetically modified corn. The goal of this prompt was to reveal whether the participants connected their molecular understanding revealed in molecular and cellular prompt 3 to explain the genetically modified corn introduced in the information paragraph.

Phase 3: Essentialist Assessment Prompts. This next phase probed for essentialist thinking in participant explanations of GMOs by introducing a second information paragraph about the genetically modified corn (Box 1). After reading the paragraph, participants responded to essentialist prompts 5 and 6 (Box 1). The first of these probed the participants to evaluate whether introducing a bacterial gene changed the fundamental nature, or essence, of the corn. The information paragraph also revealed that only the cells of the modified corn's stalk, and not the kernels, produce the desired trait. Prompt 6 evaluated whether participants asserted that only the cells that produced the toxic protein contained bacterial DNA. This assertion is consistent with essentialist thinking, because it implies the essence (the bacterial DNA) is only present where the trait appears.

Phase 4: Attitude Prompts. Two attitude prompts that elicited participants' attitudes toward GMOs were also administered. We omitted these results, because this paper focuses on conceptual ideas.
Demographic Survey. To enable making comparisons among different groups, we asked all participants to respond to questions regarding their personal and educational backgrounds. For the undergraduate student populations, the survey probed for the educational status, current class standing, current academic concentration, anticipated semester and year of graduation, birth year, and self-identified gender and ethnicity of participants. Participants were also asked to describe their career aspirations.

For biology faculty, the survey probed for the general research area, undergraduate field of study, doctoral field of study, and self-identified gender and ethnicity of faculty members.

Pilot Study for Face Validation. Before doing the research presented here, we conducted a small-scale pilot study to face validate the assessment tool. Face validation evaluated whether the participants interpreted the assessment items as intended by the researchers (Weiner and Craighead, 2010). The pilot included a small group of volunteer undergraduate students $(n=6)$ that spanned the levels of biology experience represented in this study. The pilot study verified that undergraduate students interpreted "professional colleague" as a person with a similar biology background such that they would explain the concepts as technically as they understood them. It also validated that the students interpreted the assessment prompts as the researchers intended.

\section{Assessment Implementation}

We used the novel assessment tool described above to probe undergraduate non-biology majors (NBM), entering biology majors (EBM), advanced biology majors (ABM), and biology faculty explanations of GMOs. Before completing the written assessment, undergraduate populations gave their implied consent; we informed the students that participating in the activity implied they gave us permission to include their responses in the study. The faculty signed informed consent forms as required by the institutional review board at the researchers' home institution (protocol number: X13-38, approved June 7, 2013). In the following sections, we describe how we collected undergraduate student and faculty data.

Undergraduate Student Data Collection. To collect student written assessment data, we visited an undergraduate NBM course, the first introductory biology course required for all biology majors, and an upper-division genetics course. The main researcher (L.M.P.) led the students through the assessment, one item at a time, in the order seen in Box 1. She gave them 5 minutes to complete each item before everyone moved on to the next item together, at which point they were not allowed to return to a previous item. We told the students that the assessment was not intended as a test and that there were no right or wrong answers. We asked participants to write down their thoughts in as much detail as possible. All students enrolled in the courses completed the assessment as a classroom activity for the day, but they could opt out of including their responses in the study.

Faculty Data Collection. To collect biology faculty written assessment data, we conducted the same assessment protocol 
described earlier, but in 45-minute, one-on-one meetings. The meetings took place in each faculty member's office at a convenient time.

\section{Recruitment and Participant Population}

We recruited participants from the students and faculty of a large, urban university with more than 25,000 undergraduates and $\sim 40$ faculty members in biology who are active in research and teaching and who represent a wide breadth of subdisciplines. In the following sections, we describe both the participants and the recruitment of each population.

Biological Novices-Non-biology Majors. We recruited biological novices from a biology course for nonmajors. We predicted that NBM enrolled in a biology-themed course would have the greatest interest in biology compared with other NBM populations on campus but would still have science backgrounds similar to those of the general public, because their last science courses were taken in high school. The main researcher visited all laboratory sections of the NBM course during the first week of instruction.

Undergraduate Biology Majors-Entering Biology Majors and Advanced Biology Majors. We recruited entering biology majors (EBM) from the first introductory biology course required for all biology majors. We predicted that the biology majors enrolled in this course would have an interest in biology but little experience at the university level, because the course was a prerequisite for the majority of upper-division biology courses. The main researcher visited seven out of 10 laboratory sections during the first week of instruction.

We recruited advanced biology majors (ABM) from an upper-division genetics course, the final course required for all undergraduate biology majors. We predicted that the biology majors enrolled in this course would represent the diverse interests of biology undergraduates and best represent how emerging experts nearing graduation understand GMOs. We predicted that they would explain GMOs in molecular and cellular biology terms that would align closely with biology experts' explanations. The main researcher visited all laboratory sections of the course on the final week of instruction to capture participants' ideas as late in their undergraduate biology core courses as possible.

Biological Experts-Biology Faculty. To generate an expert data set for comparison with student conceptions, we identified biology faculty who had primary research or educational interest in molecular biology, genetics, or biotechnology and contacted them via email to request their participation. These faculty represent a subset of tenured or tenure-track faculty of the biology departments at the same university as the student populations.

\section{Analysis and Comparison of Responses to Assessment Items}

For each assessment item, we constructed a concept rubric to represent the ideas given by the participants concerning their understanding of GMOs and any other major ideas that arose from the data, based on emergent themes. All written assessment data were scored such that the researcher was blinded to the respondent's population type. We revised rubrics using a subset of the data until at least two observers scored the assessments the same way $90 \%$ of the time. We performed comparative statistical analysis to determine the likelihood of statistical significance among participant populations and across assessment items. We employed Pearson's chi-square test to compare emergent themes in the written data across participant populations. JMP Pro, version 12.1.0, was used to generate all statistical comparisons (SAS Institute, 1989-2015). We determined significance from $p$ value 0.05 by applying Bonferroni corrections (see specific significance values on figures and in the narrative).

\section{RESULTS}

This study of undergraduate students' ideas about GMOs yielded multiple sources of data for analysis. In the following sections, we describe the participant populations and the analysis of the responses to each section of the novel written assessment tool. First, we present analyses of the explanations of the closed- and open-ended responses to phase 1: real-world prompts 1 and 2 to gain insights into the participant populations' explanations of GMOs without specific biological cuing. Next, we describe analyses for phase 2: molecular and cellular prompts 3 and 4 to understand the extent to which those explanations changed when cued biologically. We then show analyses for phase 3: essentialist prompts 5 and 6 to explore the extent to which participant populations evidenced essentialist thinking when explaining GMOs. The figures, tables, and results are organized to show comparisons between the four participant populations: putative novices (NBM), EBM, ABM, and putative experts (biology faculty).

\section{Description of Participant Populations}

Participation Rate and Exclusion Criteria. From an invited pool of 124 students in an NBM course, all students participated, for a $100 \%$ participation rate (Table 1 ). We excluded four participants who reported a major in biology. All 224 of the invited students enrolled in a majors' introductory biology course (EBM) participated, for a $100 \%$ participation rate. Of the $70 \mathrm{EBM}$ whose data were excluded here, 68 reported majors other than biology and two did not complete all assessment prompts. All of the invited 137 students from the upper-division genetics course (ABM) participated, for a 100\% participation rate. The 17 students whose data were not included here reported a major other than biology. No EBM or ABM reported a double major. Some students listed two biology concentrations as majors, however.

TABLE 1. Participant population

\begin{tabular}{lccccc}
\hline Participant type & Number invited & Participation rate & Sample size & Female participants & Participants of color \\
\hline NBM & 124 & $100 \%$ & 120 & $56 \%$ & $73 \%$ \\
EBM & 224 & $100 \%$ & 154 & $55 \%$ & $75 \%$ \\
ABM & 137 & $100 \%$ & 120 & $65 \%$ & $79 \%$ \\
Biology faculty & 19 & $47 \%$ & 9 & $22 \%$ & $44 \%$ \\
\hline
\end{tabular}


Of the 19 biology faculty members who were invited, nine participated for a $47 \%$ participation rate. All of the faculty participants' data were included in the study.

Populations' Reported Ethnicity and Gender. Demographics of participant populations were not statistically different in terms of gender and proportion of people of color (Table 1). We compared faculty and student populations' self-reported ethnicity and gender and determined significance from $p$ value 0.05 by applying Bonferroni corrections.

Undergraduate Student Populations' Major Concentrations. The major fields of study for NBM were $48 \%$ liberal and creative arts, $19 \%$ business, $13 \%$ undeclared, 12\% health and human services, and $8 \%$ from science and engineering in a major other than biology. Out of the eight biology concentrations offered at the study's institution, the most prevalent for EBM was physiology at $36 \%$, with general biology at $21 \%$, cellular and molecular biology at $19 \%$, and zoology at $9 \%$. For ABM, 39\% were physiology, 22\% were cellular and molecular biology, 14\% were general biology, 12\% were microbiology, and 9\% were zoology. Although there were other reported concentrations for the biology undergraduate populations, they were held by fewer than $5 \%$ of the students and thus are not listed here.

\section{Analysis of Responses to the Novel Written Assessment Tool}

Phase 1: Real-World Assessment Prompts. We predicted that biology faculty would have a higher awareness of GMOs and include more molecular and cellular processes in their explanations of GMOs due to their putative expertise in biology. Additionally, we predicted that NBM would have a lower awareness and include more organism-scale ideas in their explanations of GMOs due to their putative novice experience with biology. We predicted that ABM awareness and explanations of GMOs would be similar to those of biology faculty due to their experience with biology in their majors' courses. In contrast, we predicted that EBM awareness and explanations of GMOs would be similar to those of NBM due to their lack of exposure to university-level biology courses. For all of the following comparisons, we determined significance from $p$ value 0.05 by applying Bonferroni corrections.

Prompt 1: I have heard of a GMO. The majority of all populations had heard of a GMO: biology faculty, 100\%; ABM, 89\%; EBM, 71\%; and NBM, 63\%. Comparison of awareness of GMOs between biology faculty and ABM showed no significant differences. However, significantly more ABM had heard of a GMO than EBM $\left(\chi^{2}=13.7, d f=1, p<0.0002\right)$. Comparison between EBM and NBM showed no significant differences.

Prompt 2: How would you explain to a professional colleague what a GMO is? Here, we coded the types of rationales participants used to explain a GMO and recorded the prevalence of each rationale that emerged. We coded for three things (Table 2): whether participants included a rationale at the 1) molecular and cellular level, such as describing the insertion of a gene to build a new protein, or other examples of the

TABLE 2. Rationales offered in participants' open-ended responses to the real-world prompt "How would you explain to a professional colleague what a GMO is?"

\begin{tabular}{|c|c|c|}
\hline Cellular and molecular rationale & & Sample quote \\
\hline $\mathrm{NBM}(n=120)$ & $10 \%$ & "GMO stands for genetically modified organism. A strand of DNA is 'modified." \\
\hline $\operatorname{EBM}(n=154)$ & $18 \%$ & $\begin{array}{l}\text { "Typically, certain genes are taken from one organism and added to the DNA of another organism } \\
\text { while it is in an early developmental state." }\end{array}$ \\
\hline $\mathrm{ABM}(n=120)$ & $32 \%$ & $\begin{array}{l}\text { "An organism that has had it's genetic code modified by means other than breeding and artificial } \\
\text { selection by inserting an inducible genetic sequence not normally present in the altered } \\
\text { species." }\end{array}$ \\
\hline Faculty $(n=9)$ & $100 \%$ & $\begin{array}{l}\text { "Genetically modified organisms are those that have foreign genetic materials introduced into } \\
\text { their genomes. That is, DNA sequences have been added or deleted from the original genomes } \\
\text { (or modified/altered in a specific way)." }\end{array}$ \\
\hline Organismal rationale & & Sample quote \\
\hline NBM $(n=120)$ & $11 \%$ & $\begin{array}{l}\text { "GMO basically stands for genetically modified anything. It's different from other plants because it } \\
\text { was engineered to be resistant to something or to produce more fruit." }\end{array}$ \\
\hline $\mathrm{EBM}(n=154)$ & $11 \%$ & $\begin{array}{l}\text { "A GMO is a genetically modified organism. This means that its biological traits have been } \\
\text { tampered with to 'improve' it." }\end{array}$ \\
\hline $\mathrm{ABM}(n=120)$ & $29 \%$ & $\begin{array}{l}\text { "A GMO is a genetically modified organism-in other words, an organism which has been created } \\
\text { to have a specific advantage, e.g. resistant to parasites." }\end{array}$ \\
\hline Faculty $(n=9)$ & $0 \%$ & None \\
\hline$\underline{\text { Societal rationale }}$ & & Sample quote \\
\hline $\operatorname{NBM}(n=120)$ & $30 \%$ & $\begin{array}{l}\text { "People tend to be against them, for they have made the production of food more manipulable } \\
\text { and efficient, but they've also shown side effects for both human beings and different } \\
\text { ecosystems." }\end{array}$ \\
\hline $\operatorname{EBM}(n=154)$ & $22 \%$ & $\begin{array}{l}\text { "I've heard various theories that GMOs are harmful to the land, the human body, etc. I have also } \\
\text { read theories that GMOs aren't harmful at all. Who's to say?" }\end{array}$ \\
\hline $\mathrm{ABM}(n=120)$ & $13 \%$ & $\begin{array}{l}\text { "A GMO stands for a genetically modified organism. That's all I could say with honest scrutiny. } \\
\text { Maybe about how there's a large debate on whether humans should be eating GMOs." }\end{array}$ \\
\hline Faculty $(n=9)$ & $0 \%$ & None \\
\hline
\end{tabular}


changes happening inside the cell of a GMO; 2) organismal level, such as explaining that an organism is engineered to be resistant to something; and 3) societal level, such as explaining the public debate about GMOs.

We predicted that faculty and ABM would primarily use molecular and cellular rationales in their explanations about GMOs, while EBM and NBM would primarily use organism-level rationales. We coded for molecular and cellular processes if responses included accurate statements at the molecular and cellular level (Table 2). Some examples included "Genes are taken from one organism to another" or "DNA sequences have been added or deleted from original genomes." We found that the prevalence was $100 \%$ for biology faculty, $32 \%$ for $\mathrm{ABM}$, $18 \%$ for EBM, and 10\% for NBM. A significantly larger proportion of biology faculty included molecular and cellular processes in their responses than did ABM $\left(\chi^{2}=16.9, d f=1, p<0.0001\right.$; Figure 1A). Comparisons between ABM and EBM and between EBM and NBM showed no significant differences.

As we predicted, undergraduate student populations used organismal rationales in their explanations of GMOs (Table 2 ). We coded organismal rationales if the response included accurate statements at the organismal level. For example, some participants wrote, "Its biological traits have been tampered with to 'improve' it" and "It was engineered to be resistant to something." Unsurprisingly, no biology faculty used organismal rationales, while the undergraduate students did: $29 \%$ for $\mathrm{ABM}, 11 \%$ for $\mathrm{EBM}$, and $11 \%$ for NBM. Although no significant differences were found when comparing the use of organismal rationales between biology faculty and ABM, comparison between ABM and EBM showed a significant difference $\left(\chi^{2}=14.41, d f=1, p<0.0001\right)$. Comparison between EBM and NBM showed no significant differences.

Interestingly, undergraduate student populations also included ideas about the social response to GMOs (Table 2). For example, one student wrote, "Maybe about how there's a large debate on whether humans should be eating GMOs." Although comparisons between populations showed no significant differences, we see an increasing use of societal rationales as putative expertise decreases, with no biology faculty using societal rationales, in contrast with $13 \%$ for $\mathrm{ABM}, 22 \%$ for $\mathrm{EBM}$, and $30 \%$ for NBM.

The remaining rationales used by undergraduate student populations were described as other/don't know/blank and were used by no biology faculty, 5\% for ABM, 28\% for EBM, and $28 \%$ for NBM.

Phase 2: Molecular and Cellular Assessment Prompts. After assessing how the different populations responded to realworld prompts, we cued participants toward thinking at a molecular and cellular level by providing an information paragraph that revealed that a corn plant's DNA was modified by the insertion of a transgene (for information paragraph, see Box 1). We predicted that cuing the participants toward thinking about cellular biology might reveal an increase in the prevalence of molecular and cellular rationales used in their explanations. In particular, we predicted ABM might increase their use of molecular and cellular rationales more than EBM or NBM due to their experience in upper-division biology courses. We predicted the prevalence of molecular and cellular pro-
A How would you explain to a professional colleague what a GMO is?

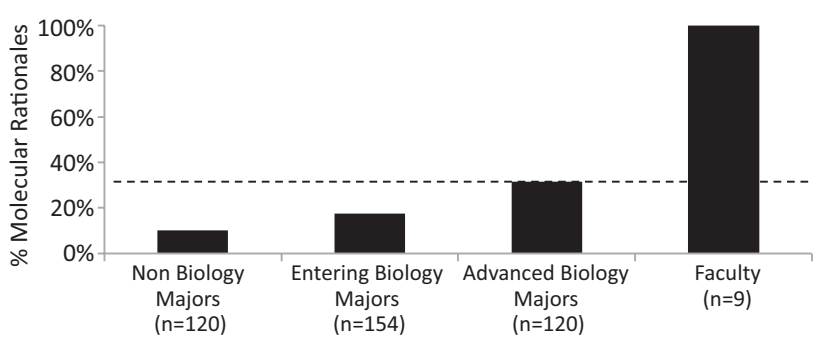

B How would you explain to a professional colleague what the relationship is between DNA and traits?

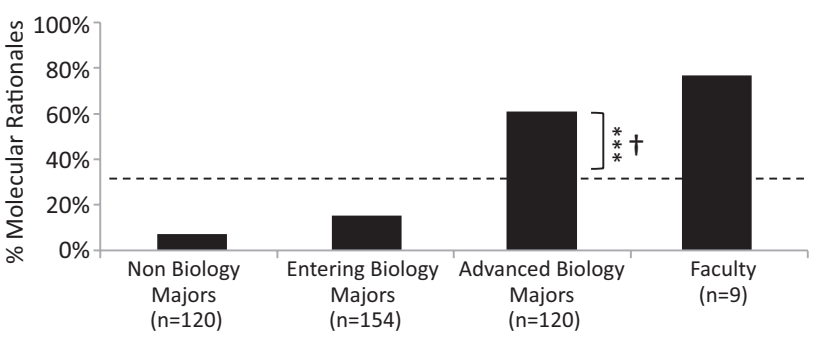

C The genetically modified corn's DNA is toxic to the insect pest that eats the corn.

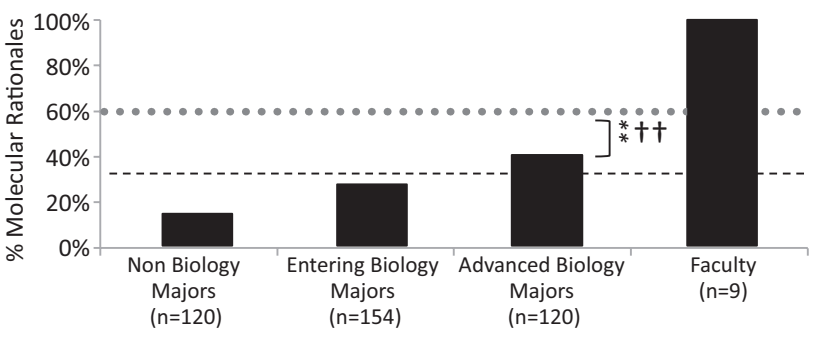

FIGURE 1. Molecular rationales included in participants' open-ended written responses to the following assessment items: (A) "How would you explain to a professional colleague what a GMO is?" The comparison between ABM and faculty is significant to $p<0.0001$ (Pearson chi-square test). (B) "How would you explain to a professional colleague what the relationship is between DNA and traits?" The comparison between EBM and ABM is significant to $p<0.0001$ (Pearson chi-square test). $t$, Comparison between $A B M$ responses in A and B. (C) "The genetically modified corn's DNA is toxic to the insect pest that eats the corn." The comparison between $A B M$ and faculty is significant to $p<0.001$ (Pearson chi-square test). $t t$, Comparison between $A B M$ responses in $B$ and $C$. The dashed line represents the percentage of $A B M$ who gave molecular rationales in $A$, and the dotted line represents the percentage of $A B M$ who gave molecular rationales in $B$. Both are displayed for ease of comparison. Pearson chi-square test: $* *, p<0.001 ; * * *, p<0.0001$.

cesses for biology faculty would be similar in their responses to both real-world and molecular and cellular assessment prompts. The prevalence of molecular and cellular processes in participant responses to molecular and cellular assessment prompts (Box 1) is shown in Figures 1, B and C, and 2. For all of the following comparisons, we determined significance from $p$ value 0.05 by applying Bonferroni corrections.

Prompt 3: How would you explain to a professional colleague what the relationship is between traits and DNA? We coded the 
types of rationales participants used to explain the relationship between traits and DNA for two things: 1) the inclusion of a molecular and cellular rationale (Figure 1B) or 2) an organism-level rationale in their explanations. We coded a response as having a molecular and cellular rationale if the participant accurately described the transcription and translation processes, that is, "Certain traits or alleles are expressed through coding of different DNA through proteins that are built" or "Traits are the phenotypic results that we see in an organism, which comes from the genes being translated into something useful for the organism (proteins, chemicals)." We did not count responses that simply included molecular words present in the text of the prompt without context, such as "gene," "DNA," "protein," or the famous "DNA $\rightarrow$ RNA $\rightarrow$ traits." We coded organism-level rationales if participants accurately explained that DNA determines traits without describing the cellular process, that is, "All traits are the result of an interaction between the genotype (DNA) and the environment" or "Traits are derived from DNA. Certain genes from DNA sequence determine trait characteristics."

The prevalence of molecular and cellular rationales for each population was $78 \%$ for biology faculty, $61 \%$ for ABM, $15 \%$ for EBM, and $8 \%$ for NBM (Figure 1B). Comparison of the inclusion of molecular and cellular rationales in their biological explanations of GMOs between biology faculty and ABM showed no significant difference (Figure 1B). However, a significantly larger proportion of ABM included molecular and cellular processes as compared with EBM $\left(\chi^{2}=62.3, d f=1\right.$, $p<0.0001$; Figure 1B).

The prevalence of organism-level rationales to describe the relationship between traits and DNA for each population was $22 \%$ for biology faculty, $26 \%$ for ABM, $48 \%$ for EBM, and $47 \%$ for NBM. Comparison between biology faculty and ABM showed no significant difference. However, a larger proportion of EBM included organismal rationales than ABM $\left(\chi^{2}=13.324\right.$, $d f=1, p<0.0003)$. Comparison between EBM and NBM showed no significant difference.

The remaining rationales used by undergraduate student populations were described as other/don't know/blank and were used by no biology faculty, $5 \%$ for ABM, $18 \%$ for EBM, and $28 \%$ for NBM.

Prompt 4: The genetically modified corn's DNA is toxic to the insect pest that eats the corn. In response to this scientifically inaccurate statement, we predicted that the putative expertise of biology faculty would allow them to distinguish between the roles of DNA and protein to assert that the toxic protein, rather than the DNA itself, is what is toxic to the insect pest. We predicted $A B M$ to respond similarly to faculty and that NBM and EBM, each with little university-level biology experience, would likely agree with the scientifically inaccurate statement, based on the information paragraph that asserts the transgene inserted in the corn's genome produces a trait that is toxic to the insect pest. Below we show the analysis of the closed- and open-ended responses to prompt 4.

Closed-Ended Responses. A majority of students across all undergraduate populations agreed with the scientifically inaccurate statement that the corn's DNA is toxic to the insect pest, while no biology faculty did (Figure 2A); $48 \%$ of ABM, $62 \%$ of EBM, and $67 \%$ of NBM agreed. A significantly larger portion of ABM agreed with the inaccurate statement than faculty $\left(\chi^{2}=7.904\right.$, $d f=1, p<0.0049$; Figure 2A). When compared, there were no significant differences between ABM and EBM or between EBM and NBM.

Less than half of all undergraduate populations disagreed with the inaccurate statement, while all biology faculty did, with $42 \%$ for ABM, $28 \%$ for EBM, and $17 \%$ for NBM. Significantly more biology faculty disagreed as compared with $\mathrm{ABM}\left(\chi^{2}=\right.$ 11.479, $d f=1, p<0.0007$; Figure 2A). There were no significant differences between ABM and EBM or between EBM and NBM.

Open-Ended Responses. We analyzed the open-ended explanations in response to "The DNA is toxic to the insect pest that eats the corn" for molecular and cellular rationales. We coded a response as a molecular and cellular rationale if the participant was able to distinguish between DNA and its products. For example, one participant wrote "The DNA is not toxic, but the products produced by the gene (DNA) are what make it toxic." Here is what we found.

Unsurprisingly, as putative expertise increases, so does the proportion of participants who use molecular and cellular rationales, with $100 \%$ of biology faculty, $40 \%$ of ABM, $26 \%$ of EBM, and $14 \%$ of NBM including such rationales (Figure 1C). A significantly larger proportion of biology faculty included molecular and cellular rationales when compared with $\mathrm{ABM}\left(\chi^{2}=\right.$ 12.221, $d f=1, p<0.0005)$. There were no significant differences between ABM and EBM and EBM and NBM.

The remaining rationales used by undergraduate student populations were described as other/don't know/blank (unpublished data). There were no significant differences among populations.

Comparison of Closed-Ended and Open-Ended Responses. We predicted that those who disagreed with the scientifically inaccurate statement would include a cellular and molecular rationale in their open-ended explanations. Specifically, we hypothesized that they would assert that the trait is toxic, not the DNA itself. Indeed, those who included a molecular and cellular rationale in their explanations were statistically more likely to have disagreed than to have agreed (ABM: $\chi^{2}=100.224, d f=1, p<$ 0.0001; EBM: $\chi^{2}=121.050, d f=1, p<0.0001$; NBM: $\chi^{2}=$ $81.928, d f=1, p<0.0001$; Figure 2B). One hundred percent of faculty disagreed with the statement and also included a cellular and molecular rationale in their explanations.

Comparison of the Use of Molecular and Cellular Rationales across Prompts 2, 3 and 4. We predicted ABM might increase their use of molecular and cellular rationales more than EBM or NBM when prompted with biological cues, due to their experience with more university-level biology courses. Here, we compared the prevalence of molecular and cellular rationales in participant responses to real-world prompt 2, "How would you explain to a professional colleague what a GMO is?," and their explanations of cellular and molecular prompt 3, "How would you explain to a professional colleague what the relationship is between traits and DNA?" Here is what we found.

Biology faculty showed no significant difference in the use of molecular and cellular rationales in their explanations 
A Closed-ended responses: The genetically modified corn's DNA is toxic to the insect pest that eats the corn (scientifically inaccurate).

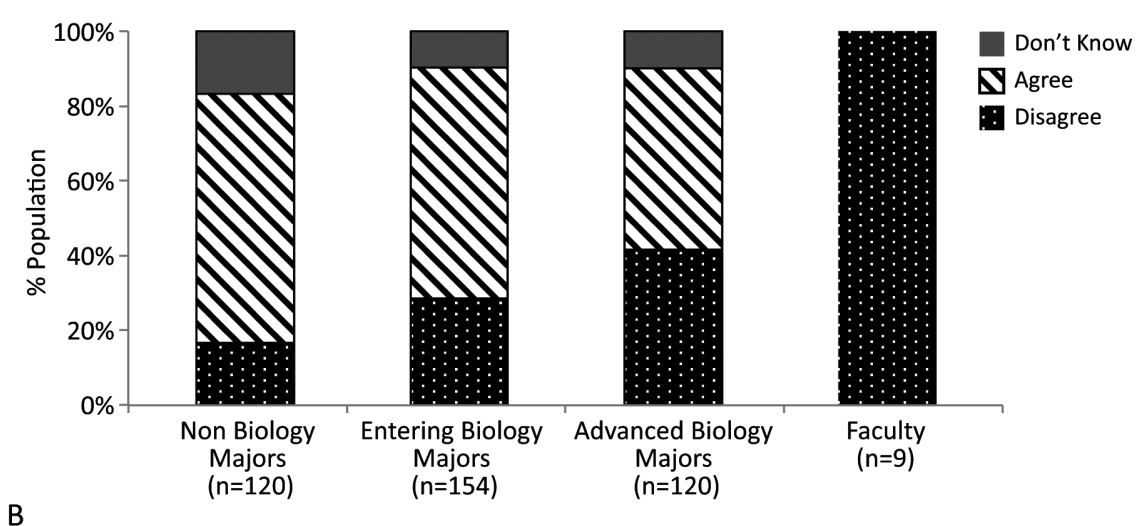

Open-ended responses that included a cellular and molecular rationale

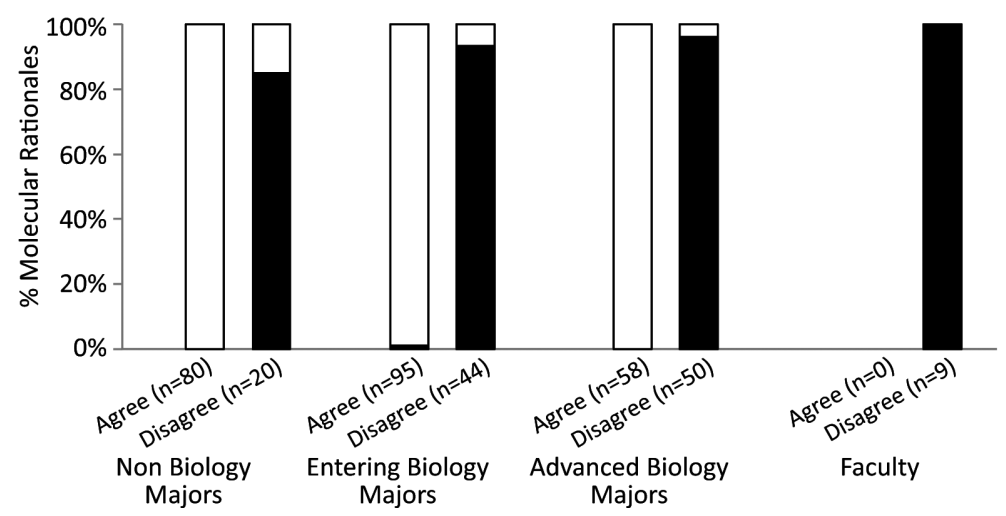

FIGURE 2. Participants' responses to molecular and cellular assessment prompt 4: "The genetically modified corn's DNA is toxic to the insect pest that eats the corn." (A) Closed-ended scale: disagree (scientifically accurate; dotted), agree (scientifically inaccurate; striped), don't know (gray). The difference between ABM and faculty in the percentage of people who responded "disagree" was significant to $p<0.001$ (Pearson chi-square test). The difference between $A B M$ and faculty in the percentage of people who responded "agree" was significant to $p<0.005$ (Pearson chi-square test). (B) Participants who included molecular and cellular rationales in open-ended responses (black) were significantly more likely to disagree (the scientifically accurate response) than to agree. All comparisons significant to $p<0.0001$.

between their real-world explanations and molecular and cellular explanations (Figure 1B). Strikingly, twice as many $\mathrm{ABM}$ included molecular and cellular processes when cued $\left(\chi^{2}=21.696, d f=1, p<0.0001\right.$; Figure 1B). There were no significant differences between explanations for faculty, EBM, or NBM.

We were also interested in whether participants who exhibited an understanding of the central dogma at a molecular and cellular level would transfer that knowledge to understanding GMOs, a real-world phenomenon. For those who used molecular and cellular rationales to explain the relationship between traits and DNA in response to prompt 3, you might predict that they would also include molecular and cellular rationales in responses to prompt 4, "The genetically modified corn's DNA is toxic to the insect pest that eats the corn."

However, when comparing the two, we found significantly fewer molecular and cellular rationales in $\mathrm{ABM}$ responses $\left(\chi^{2}=11.270, d f=1, p<0.0008\right.$; Figure 1C). There were no significant differences in faculty, EBM, and NBM.

Phase 3: Essentialist Prompts. To cue participants toward revealing essentialist thinking, we provided an information paragraph (for information paragraph, see Box 1). We predicted that putative biology experts would avoid using essentialist thinking when explaining GMOs due to their experience in molecular and cellular biology. In contrast, we predicted that putative novices in biology would use essentialist thinking in their explanations of GMOs due to their tendency to explain GMOs using organismal rationales. However, it was unclear whether $\mathrm{ABM}$, the undergraduate student population with the most putative biology expertise, would show evidence of essentialist thinking, and how this population would compare with EBM. Analysis of the prevalence of essentialist thinking is shown in Figures 3 and 4 and Table 3. For all of the following comparisons, we determined significance from $p$ value 0.05 by applying Bonferroni corrections.

Prompt 5: I consider this genetically modified corn with a bacterial gene to be: a variety of corn, a variety of bacteria, a hybrid of corn and bacteria, or neither corn nor bacteria. The analysis of essentialist prompt 5 (Box 1) excludes the responses "a variety of bacteria" and "neither corn nor bacteria," because these accounted for less than $5 \%$ of participant responses. Below, we show our analysis of participants who asserted the genetically modified corn was a variety of corn and the rationales used in the open-ended responses defending their choice. We predicted that those who chose this response would include cellular and molecular rationales in their explanations. Next, we show our analysis of responses from participants who asserted the genetically modified corn was a hybrid of corn and bacteria and the rationales used in the open-ended responses defending their choice. We predicted that those who chose a hybrid of corn and bacteria would exhibit essentialist rationales. Here is what we found.

Closed-Ended Responses-A Variety of Corn. We expected that putative experts would assert that this genetically modified corn is a variety of corn, while putative novices would assert that this is a hybrid of corn and bacteria, the response that exhibits evidence of essentialist thinking. Indeed, we found that biology faculty all chose a variety of corn, while only $42 \%$ of ABM, $19 \%$ of EBM, and $25 \%$ of NBM did (Figure 3A). A significantly larger proportion of biology faculty asserted that this was a variety of corn when compared with $\mathrm{ABM}$ 
A Closed-ended response: I consider this genetically modified corn with a bacterial gene to be:

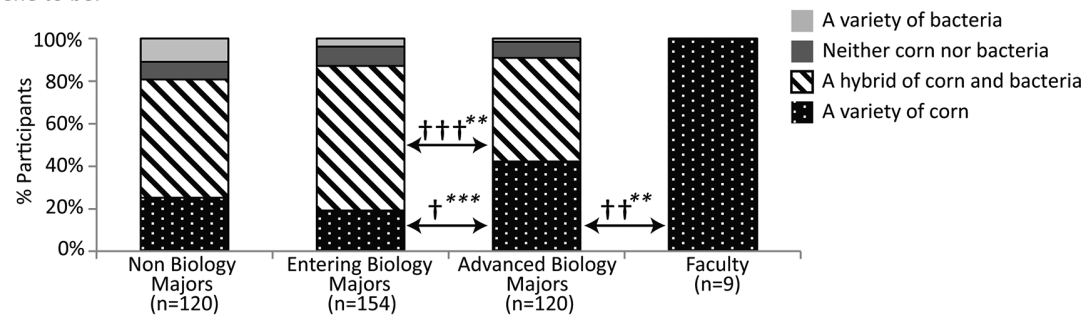

B Molecular and cellular rationales included in the open-ended responses of participants who chose: "A variety of corn."

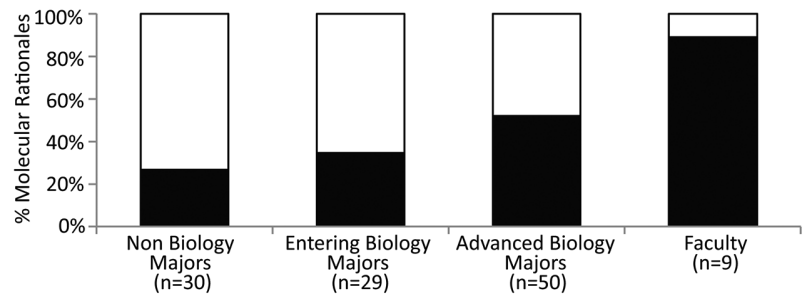

C Essentialist rationales included in the open-ended responses of participants who chose: "A hybrid of corn and bacteria."

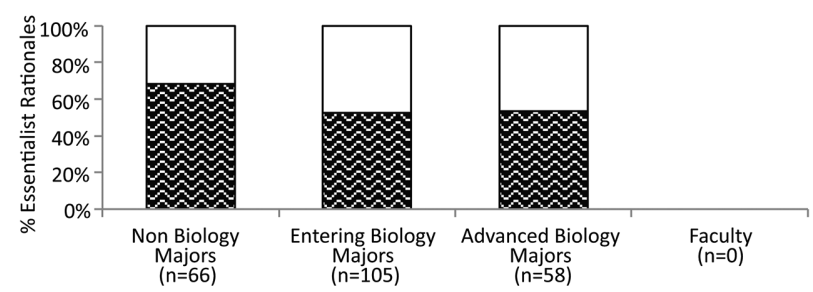

FIGURE 3. Participants' responses to essentialist assessment prompt 5: "I consider this genetically modified corn with a bacterial gene to be..." (A) Closed-ended scale: a variety of corn (scientifically accurate; dotted; $t$, comparison between EBM and ABM; †t, comparison between $A B M$ and faculty), a hybrid of corn and bacteria (essentialist; striped; $\mathrm{ttt,} \mathrm{comparison} \mathrm{between} \mathrm{EBM} \mathrm{and} \mathrm{ABM),} \mathrm{neither} \mathrm{corn} \mathrm{nor} \mathrm{bacteria} \mathrm{(dark} \mathrm{gray),} \mathrm{or} \mathrm{a} \mathrm{variety}$ of bacteria (light gray). (B) Of the participants who chose "a variety of corn," those who included a molecular and cellular rationale (black). (C) Of the participants who chose "a hybrid of corn and bacteria," those who included an essentialist rationale (zigzag pattern). Pearson chi-square test: **, $p<0.001 ; * * *, p<0.0001$.

$\left(\chi^{2}=11.479, d f=1, p<0.0007\right.$; Figure 3A). Additionally, a significantly larger proportion of ABM than EBM asserted that the genetically modified corn was a variety of corn $\left(\chi^{2}=\right.$ 17.140, $d f=1, p<0.0001$; Figure 3A). Comparison between EBM and NBM showed no significant differences.

Open-Ended Responses-A Variety of Corn. We analyzed the open-ended explanations of those who asserted the genetically modified corn was a variety of corn to test our hypothesis that those who chose "a variety of corn" would defend their choice with molecular and cellular rationales (Figure 3B). For example, one participant wrote, "It still contains most of the genetic information that regular corn does. It only has the one gene from the bacteria, but does not share its DNA." Another wrote, "One gene mutation (whether man made or no) does not change the basic species of the "original plant." This is what we found.

Indeed, $88.9 \%$ of faculty who chose "a variety of corn" included a molecular and cellular rationale in their open-ended explanations (Figure 3B), and among student populations, $52 \%$ of $\mathrm{ABM}, 34 \%$ of EBM, and $27 \%$ of NBM included a molecular and cellular rationale.

Participants also included organismal rationales in their explanations for choosing "a variety of corn." We coded an organismal rationale if the participant reasoned that it still looked and acted like corn. For example, one person said, "Unless they really blew it, would still look and act like corn and taste like corn. Difference should be detectable only biochemically and by pest resistance." Although there was no significant difference between populations, a smaller proportion of biology faculty (11.11\%) included organismal rationales compared with the undergraduate populations, with $\mathrm{ABM}$ at $34 \%, \mathrm{EBM}$ at $45 \%$, and NBM at $43 \%$.

The remaining rationales included a unique rationale, or the participants said they did not know or left the space blank.

Closed-Ended Responses-A Hybrid of Corn and Bacteria. More than half of all undergraduate populations indicated that genetically modified corn is a hybrid of corn and bacteria. While no biology faculty asserted this, $49 \%$ of $\mathrm{ABM}, 68 \%$ of $\mathrm{EBM}$, and $56 \%$ of NBM did. Significantly more EBM chose that the genetically modified corn was hybrid than $\mathrm{ABM}\left(\chi^{2}=10.287, d f=1, p<\right.$ 0.0013 ; Figure $3 \mathrm{~A}$ ). There were no significant differences between faculty and $\mathrm{ABM}$ or EBM and NBM.

Open-Ended Responses-A Hybrid of Corn and Bacteria. We analyzed the open-ended explanations of those who asserted that the genetically modified corn was a hybrid of corn and bacteria to test our hypothesis that those who chose this would include an essentialist rationale in their openended explanations (Figure 3C). We coded an essentialist rationale if the participant explained that the organism was a mix of bacteria and corn. For example, one participant said, "I consider this a hybrid because it is no longer just one thing-it is not just bacteria nor is it just corn, but it is a combination of two things."

The majority of all student populations who chose "a hybrid of corn and bacteria" included an essentialist rationale in their open-ended explanations, with no significant differences between populations (Figure 3C).

The remaining rationales included a unique rationale, or the participants said they did not know or left the space blank.

Prompt 6: The bacterial gene is present in the cells of all parts of the genetically modified corn. We predicted that putative biology experts would agree with this scientifically accurate statement, because they would use their knowledge of cellular and 
A Close-ended Responses: The bacterial DNA is present in the cells of all the parts of the genetically modified corn.

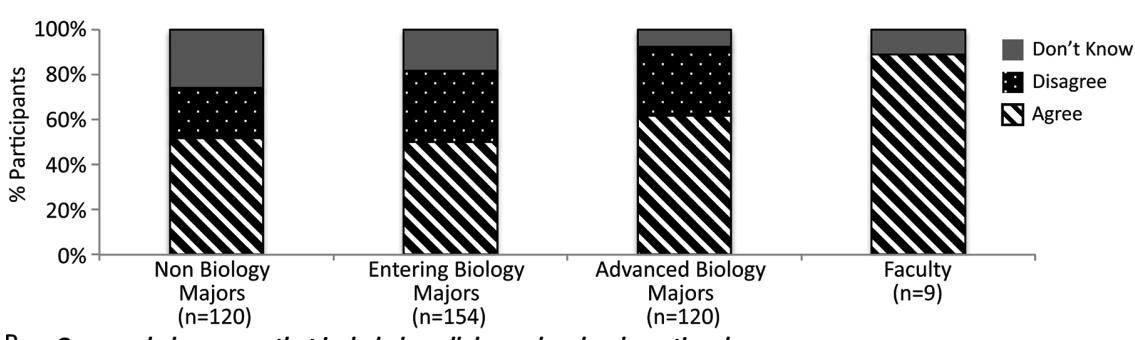

B Open-ended response that included a cellular and molecular rationale

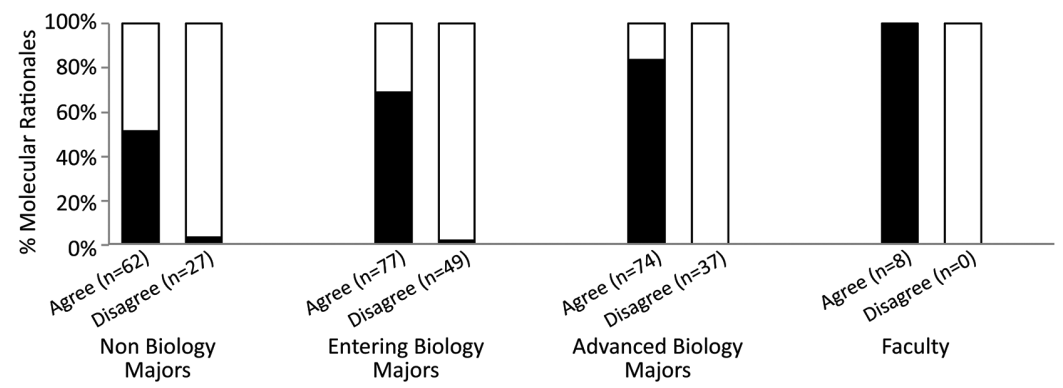

C Open-ended responses that included an essentialist rationale

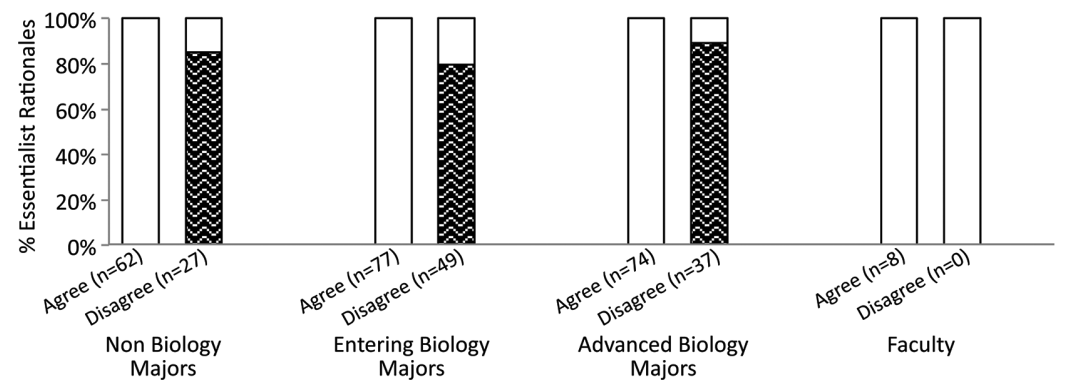

FIGURE 4. Participants' responses to essentialist assessment prompt 6: "The bacterial DNA is present in the cells of all the parts of the genetically modified corn."

(A) Closed-ended scale: agree (scientifically accurate; striped), disagree (essentialist; dotted), don't know (dark gray). (B) Participants who included a molecular and cellular rationale (black) were significantly more likely to agree (which is scientifically accurate) than to disagree (Pearson chi-square test: $p<0.0001$ ). (C) Participants who included an essentialist rationale (zigzag pattern) were significantly more likely to disagree (which is scientifically inaccurate) than to agree (Pearson chi-square test: $p<0.0001$ ).

molecular biology to assert that DNA is the same in all the cells of an organism, regardless of the cell type. On the other hand, we predicted that a putative novice would use the information paragraph to disagree and assert that the bacterial gene is only present in the cells of the genetically modified corn's stalk, because those are the only cells that produce the toxic protein (for information paragraph, see Methods). We consider this rationale evidence of essentialist thinking, because it uses the outward characteristics of the cell (producing the toxic trait) to infer that the essence of that cell, its DNA, is distinct from the cells that do not produce this toxin. However, it is unclear how ABM would respond to this prompt and whether their responses would differ from EBM. In the following sections, we show analysis of the closed-ended responses and open-ended rationales for prompt 6 (Box 1).

Closed-Ended Responses. The majority of all populations agreed to the scientifically accurate challenge statement (Figure 4A). Comparison between all populations showed no significant differences. However, at least $20 \%$ of each undergraduate population disagreed with this scientifically accurate statement, with no biology faculty, $31 \%$ of $\mathrm{ABM}, 32 \%$ of $\mathrm{EBM}$, and $23 \%$ of NBM disagreeing (Figure 4A).

Comparison of Closed- and Open-Ended Responses to Prompt 6. We predicted that those who agreed to the scientifically accurate statement would assert that the bacterial gene is in all the cells of the genetically modified corn, because the DNA is the same in all cells and the toxic protein is expressed only in the genetically modified corn's stalk. Indeed, we found that those who included this cellular and molecular rationale were statistically more likely to have chosen agree than disagree (ABM: $\chi^{2}=70.224, d f=1, p<0.0001$; EBM: $\chi^{2}=$ 54.545, $d f=1, p<0.0001$; NBM: $\chi^{2}=$ 21.645, $d f=1, p<0.0001$; Figure 4B).

We predicted that those who disagreed with the scientifically accurate statement, "The bacterial gene is present in the cells of all parts of the genetically modified corn," would assert the essentialist rationale that the bacterial gene is only present in the cells of the genetically modified corn's stalk, because those are the only cells that produce the toxic protein. Indeed, we found that those who included this essentialist rationale were statistically more likely to have disagreed than to have agreed (ABM: $\chi^{2}=70.528$, $d f=1, p<0.0001$; EBM: $\chi^{2}=88.759, d f=1, p<0.0001$; NBM: $\chi^{2}$ $=70.528, d f=1, p<0.0001$; Figure 4 C).

TABLE 3. Rationales offered by those who responded to the prompt "I consider this genetically modified corn with a bacterial gene to be..." by choosing the essentialist response "a hybrid of corn and bacteria"

\begin{tabular}{lll}
\hline Essentialist rationale & & Sample quote \\
\hline NBM $(n=66)$ & $68 \%$ & "They mixed the genes from the corn and bacteria which cause a hybrid of corn and bacteria." \\
EBM $(n=105)$ & $52 \%$ & "I would say that GMO corn is a hybrid of both bacteria and corn because it exhibits traits of both the corn and \\
bacteria." & "I consider this to be a hybrid because it is no longer just one thing-it is not just a bacteria nor is it just a corn, \\
but a combination." & None $(n=58)$ & $53 \%$
\end{tabular}


The remaining rationales included a unique rationale, or the participants said they did not know or left the space blank.

\section{DISCUSSION}

This study investigated how biology faculty, undergraduate biology majors, and nonbiology majors conceptualized GMOs and the extent to which these populations used molecular processes to explain this biotechnology. Additionally, the research investigated the extent to which essentialist thinking persists among participant populations in their explanations of GMOs. Here, we present our main findings, along with conclusions and directions for future investigations into students' conceptions and misconceptions of GMOs.

\section{Undergraduate Biology Majors Rarely Described the Molecular Changes Happening inside Cells in Their Initial Explanations of GMOs}

Our findings revealed that undergraduate biology majors rarely used molecular and cellular processes to explain GMOs as they would in everyday life. After looking at a real advertisement containing the phrase "non-GMO corn," the majority of all three undergraduate student populations described GMOs in terms of the outward characteristics resulting from genetic modification rather than the molecular changes happening inside the cell. We were particularly surprised by the ABM explanations. We predicted that $A B M$ would use their increased experience with biology to explain GMOs more similarly to how biology faculty described them: that modifying genes or DNA will result in a new protein and associated traits. This was not the case-only $32 \%$ of ABM included molecular processes in their initial explanations of GMOs (Figure 1A).

Was this because ABM lack the conceptual knowledge needed to understand genetic modification at a cellular level? Our results suggest that this was not the case. ABM appeared to possess knowledge of the cellular processes required to understand genetic modification when describing the relationship between traits and DNA (Figure 1B), but neglected to apply that knowledge in the real-world context of GMOs. One reason for this could be that the undergraduate students did not have the opportunity to apply their newly acquired molecular knowledge in the classroom to real-world issues. Previous research supports this finding; one study showed that students in an environmental studies program were better able to make connections between their course work and a real-world science problem, ocean acidification, than students in biology or chemistry majors (Danielson and Tanner, 2015). The authors argued that the environmental studies curriculum might be more interdisciplinary and gives students many opportunities to integrate concepts between real-life and basic science. Without practice in the college classroom, biology majors may not recognize that the GMOs are associated with their school science, and instead rely on information they have encountered in their everyday life outside the classroom, such as debates about the social response to GMOs.

Our findings also indicated that, despite showing an understanding of the central dogma at a cellular level, participants did not necessarily apply that understanding when responding to the scientifically inaccurate statement, "The genetically modified corn's DNA is toxic to the insect pest that eats the corn" (Figure 2). This was surprising, as we predicted that those with molecular knowledge of DNA would catch the inaccuracy that the DNA molecule exhibits the toxicity, rather than the protein for which the molecule codes. However, it appears this was not the case.

Previous research supports this finding that students do not readily apply their biology knowledge while explaining complex biological processes (Marbach-Ad, 2010; Newman et al., 2012). Experts, on the other hand, are able to integrate their explanations of molecular and cellular mechanisms into a wider biological or social context (Southard et al., 2016). The central dogma that describes how information is stored in DNA, copied into RNA, and used to build proteins that carry out cellular functions is difficult for undergraduate students to understand (Newman et al., 2016). Research has shown that students' confusion about genes and proteins may prevent their ability to reason through various genetic phenomena (Duncan and Reiser, 2007) and that teachers can address the confusion directly in the classroom (Thorne and Gericke, 2014). Research has shown that biology educators who use real-world issues in the classroom can be effective in bridging the gap between school science and the students' real-world experiences (Wu, 2013). Our findings suggest that this novel assessment tool could be used to assess student understanding of GMOs and provide the opportunity for biology students to connect lessons about genetic modification in the classroom to the real-world issue of GMOs.

The current findings, along with those presented in related publications (Danielson and Tanner, 2015; Richard et al., 2017), suggest that science instructors may overestimate the amount of biological knowledge their students hold. This study, while it focuses only on GMOs, raises a larger issue of instructors' assumptions of student understanding and expertise. This issue warrants continued attention not just in biology but across science, technology, engineering, and mathematics education.

\section{The Majority of All Undergraduate Student Populations Evidenced Essentialist Thinking in Explaining GMOs}

Our results indicated that all undergraduate student populations used essentialist reasoning in their explanations of GMOs (Figures 3 and 4). The majority of all student populations asserted that a genetically modified corn with a bacterial gene is a hybrid of corn and bacteria, while no biology faculty asserted this. Rather, biology faculty used their knowledge of DNA to assert that changing one gene in an organism would not fundamentally change the organism itself.

Previous research supports the finding that the perception of hybrids is rooted in essentialism; if DNA is considered to be an organism's essence, and essence cannot be divided or shared, an organism with the genes of two species cannot be placed into a specific, essential category, and is thus a hybrid (Wagner et al., 2010). It has been documented that students may think of DNA as an organism's essence and the traits the cell exhibits as the "outward characteristics" (Gelman and Rhodes, 2012), which could inhibit students' understanding of the central dogma (Coley and Tanner, 2012).

\section{The Ability to Reason on a Molecular Level Was Associated with Scientific Accuracy, While Essentialist Thinking Was Associated with Misconceptions}

Our results indicated that molecular rationales were associated with scientifically accurate ideas, regardless of the participants' level of biology expertise. When we looked at those 
who disagreed with the scientifically inaccurate statement "The genetically modified corn's DNA is toxic to the insect pest that eats the corn," almost every participant's response included a molecular and cellular rationale (Figure 2B). This pattern emerged again in response to "The bacterial DNA is present in the cells of all the parts of the genetically modified corn." Of the participants who included a molecular rationale, only two participants disagreed with the scientifically accurate statement (Figure 4B).

In contrast, our results showed that holding misconceptions appeared to be associated with essentialist thinking. We predicted that, if essentialist thinking was present, participants would disagree with the scientifically accurate statement, "The bacterial gene is present in the cells of all the parts of the genetically modified corn," because they would assert that the DNA would only be present where the outward trait is expressed, in the corn's stalk. In our study, at least $20 \%$ of all student populations disagreed with the scientifically accurate statement (Figure 4A). The majority of those who disagreed defended their choice by explaining that the bacterial DNA was only present in the cells of the corn's stalk, where the plant exhibited the toxic trait (Figure 4C). These findings support the idea that persistent scientifically inaccurate ideas could be rooted in essentialist thinking (Coley and Tanner, 2015). Addressing essentialist thinking in the classroom could help educators improve undergraduate understanding of genetic information flow.

\section{CONCLUSIONS}

Our results revealed that undergraduate biology majors rarely described the molecular changes happening inside cells in their initial explanations of GMOs. Despite ABM demonstrating that they have much of the biology knowledge necessary to understand genetic modification at a cellular level, they did not appear to apply this knowledge when explaining GMOs. Further, this study showed that all undergraduate student populations exhibited evidence of essentialist thinking while explaining GMOs, regardless of their level of biology training. This is consistent with the idea that essentialism may be associated with student misconceptions of the central dogma (Coley and Tanner, 2012) and may contribute to the public's mistrust of the technology (Wagner, 2010). Additionally, our study uncovered an association between scientifically accurate ideas and the application of molecular and cellular rationales and an association between misconceptions and essentialist rationales.

This study investigated undergraduate biology students' conceptions of GMOs, and how those conceptions fit in the spectrum of biology expertise. However, this study represents only the conceptions of undergraduate nonmajors, biology majors, and faculty from one institution and should be explored across a broader range of disciplines and contexts. The authors omitted participant attitudes toward GMOs from the analysis to focus on conceptual understanding. However, future studies could assess the extent to which attitudes influence explanations of GMOs. Future investigations could aid scientists and instructors in better understanding the barriers to achieving a scientifically accurate understanding of GMOs and encourage more expert thinking in undergraduate biology students. If undergraduate biology students do not understand genetic modification, then who will?

\section{ACKNOWLEDGMENTS}

This research was supported by National Science Foundation CAREER award DRL-0954127 to K.D.T. We thank the faculty and students who participated in the study; Dr. Zheng-Hui He and Kathryn Danielson; members of SEPAL: Science Education Partnership and Assessment Laboratory in the Department of Biology at San Francisco State University for helpful discussions; and the monitoring editor and anonymous reviewers for helpful comments and suggestions.

\section{REFERENCES}

Agorram, B., Clement, P., Selmaoui, S., Khzami, S. E., Chafik, J., \& Chiandli, A (2010). University students' conceptions about the concept of gene: Interest of historical approach. US-China Education Review, 7(2), 9-15.

Alberts, B., Beachy, R., Baulcombe, D., Blobel, G., Datta, S., Fedoroff, N., .. Sharp, P. (Ed.). (2013). Standing up for GMOs. Science, 341, 1320.

American Association for the Advancement of Science. (2011). Vision and Change in Undergraduate Education: A Call to Action. Washington, DC. Retrieved July 18, 2017, from http://visionandchange.org/finalreport

Bedard, J., \& Chi, M. T. H. (1992). Expertise. Current Directions in Psychological Science, 1, 135-139.

Bowling, B. V., Acra, E. E., Wang, L., Myers, M. F., Dean, G. E., Markle, G. C., .. Huether, C. A. (2008). Development and evaluation of a genetics literacy assessment instrument for undergraduates. Genetics, 178(1), 15-22.

Coley, J. D., \& Tanner, K. D. (2012). Common origins of diverse misconceptions: Cognitive principles and the development of biology thinking. CBE-Life Sciences Education, 11, 209-215.

Coley, J. D., \& Tanner, K. D. (2015). Relations between intuitive biological thinking and biological misconceptions in biology nonmajors. CBE-Life Sciences Education, 14(1), ar8.

Danielson, K. I., \& Tanner, K. D. (2015). Investigating undergraduate science students' conceptions and misconceptions of ocean acidification. CBELife Sciences Education, 14(3), ar29.

Dawson, V. (2007). An exploration of high school (12-17 year old) students understandings of, and attitudes towards biotechnology processes. Research in Science Education, 37, 59-73.

Dawson, V., \& Schibeci, R. (2003). Western Australian high school students attitudes towards biotechnology processes. Journal of Biological Education, 38, 6-12

Duncan, R. G., \& Reiser, B. J. (2007). Reasoning across ontologically distinct levels: Students' understandings of molecular genetics. Journal of Research in Science Teaching, 44(7), 938-959.

Fields of Gold. [Editorial]. (2013, May 2). GM Crops: Promise \& Reality [Special Issue]. Nature, 497(7447), 5-6.

Gelman, S. A. (2003). The essential child: Origins of essentialism in everyday thought. New York: Oxford University Press.

Gelman, S. A., \& Rhodes, M. (2012). "Two thousand years of stasis": How psychological essentialism impedes evolutionary understanding. In Rosengren, K. S., Brem, S., Evans, E. M., \& Sinatra, G. (Eds.), Evolution challenges: Integrating research and practice in teaching and learning about evolution (pp. 3-21). New York: Oxford University Press.

Legge, J. S. Jr., \& Durant, R. F. (2010). Public opinion, risk assessment and biotechnology: Lessons from attitudes toward genetically modified foods in the European Union. Review of Policy Research, 27, 59-76.

Marbach-Ad, G. (2010). Attempting to break the code in student comprehension of genetics concepts. Journal of Biological Education, 35(4), 183-189.

National Academies of Sciences, Engineering, and Medicine. (2016). Engineered crops: Experiences and prospects. Washington DC: National Academies Press.

Newman, D. L., Catavero, C. M., \& Wright, L. K. (2012). Students fail to transfer knowledge of chromosome structure to topics pertaining to cell division. CBE-Life Sciences Education, 11, 425-426.

Newman, D. L., Snyder, C. W., Fisk, J. N., \& Wright, L. K. (2016). Development of the Central Dogma Concept Inventory (CDCI) assessment tool. CBELife Sciences Education, 15(2), ar9. 
Richard, M., Coley, J. D., \& Tanner, K. D. (2017). Investigating undergraduate students' use of intuitive reasoning and evolutionary knowledge in explanations of antibiotic resistance. CBE-Life Sciences Education, 16, ar55.

Sadler, T. D. (2004). Informal reasoning regarding socioscientific issues: A critical review of research. Journal of Research in Science Teaching, 41(5), 513-536.

Sadler, T. D., \& Zeidler, D. L. (2004). The morality of socioscientific issues: Construal and resolution of genetic engineering dilemmas. Science Education, 88(1), 4-27.

SAS Institute. (1989-2015). JMP Pro (version 12.1.0). Cary, NC.

Sinatra, G. M., Kienhues, D., \& Hoferm, B. K. (2014). Addressing challenges to public understanding of science: Epistemic cognition, motivated reasoning, and conceptual change. Educational Psychologist, 49, 123-138.

Smith, M. K., \& Knight, J. K. (2012). Using the Genetics Concept Assessment to document persistent conceptual difficulties in undergraduate genetics courses. Genetics, 191, 21-32.

Smith, M. K., Wood, W. B., \& Knight, J. K. (2008). The Genetics Concept Assessment: A new concept inventory for gauging student understanding of genetics. CBE-Life Sciences Education, 7, 422-430

Southard, K., Wince, T., Meddleton, S., \& Bolger, M. S. (2016). Features of knowledge building in biology: Understanding undergraduate students ideas about molecular mechanisms. CBE-Life Sciences Education, 15(1), ar7.

Stewart, C. N., Harold, A. R., \& Halfhill, M. D. (2000). Transgenic plants and biosafety: Science, misconceptions, and public perceptions. BioTechniques, 29, 832-843.
Thorne, K., \& Gericke, N. (2014). Teaching genetics in secondary classrooms: A linguistic analysis of teachers' talk about proteins. Research in Science Education, 44, 81-108.

Tibel, L. A. E., \& Rundgren, C. (2010). Educational challenges of molecular life science: Characteristics and implications for education and research. CBE-Life Science Education, 9, 25-33

UK Department of Business Enterprise and Regulatory Reform and Sciencewise. (2009). Public Perceptions of Industrial Biotechnology. Retrieved July 18, 2017, from www.sciencewise-erc.org.uk/cms/assets/Uploads/ Project-files/final-report.pdf

Wagner, W., Kronberger, N., Nagata, M., Sen, R., Holtz, P., \& Flores Palacios, F. (2010). Essentialist theory of "hybrids": From animal kinds to ethnic categories and race. Asian Journal of Social Psychology, 13, 232-246.

Weiner, I. B., \& Craighead, E. W. (2010). The Corsini encyclopedia of psychology (4th ed.). Hoboken, NJ: Wiley, 637-638.

Wu, Y. (2013). University students' knowledge structures and informal reasoning on the use of genetically modified foods: Multidimensional analyses. Research in Science Education, 43, 1873-1890.

Wunderlich, G., \& Gatto, K. A. (2015). Consumer perception of genetically modified organisms and sources of information. Advances in Nutritional 7(6), 842-851.

Zeidler, D. L., Sadler, T. D., Simmons, M. L., \& Howes, E. V. (2005). Beyond STS A research-based framework for socioscientific issues education Science Education, 89, 357-377. 